\title{
Stability and Change during Periods of Re-organisation: A Cultural Historical Investigation into Children's Services (in England)
}

\author{
Paul Wiseman \\ University of Wolverhampton, United Kingdom
}

\begin{abstract}
This paper presents the findings of a quasilongitudinal investigation of the lived experiences of Children's Service professionals (in England) between 2004 and 2012. The research aimed to gain an understanding of the factors which shape and transform collective professional behaviour during periods of national policy reform. Cultural historical activity theory formed the analytical framework which helped identify features of professional practice which changed or remained the same; thereby giving insight into 'the change process' within large organisations. The findings identified $a$ movement from universal provision of services to one that adopted an increasingly business orientated approach. Multi-agency partnership working remained evident throughout; from policy ambition in 2004 to one embedded in practice through necessity within an environment of decreasing financial and human resources.
\end{abstract}

\section{Introduction}

This article is based upon research undertaken as part of my doctoral thesis which attempted to develop an understanding of the factors which have shaped professional behaviour during two separate and distinct periods within the recent history of Children's Services in England. For the purpose of this study Children's Services are defined as those which were located within the Children's Trust arrangements which were introduced following the introduction of the Children Act, 2004 [11] which amalgamated two previously independent statutory agencies; the Local Education Authority and Children's Social Care with a range of voluntary sector organisations involved in the provision of an extended range of services for all children, young people.

The research followed a quasi - longitudinal design, in that it is based upon studies of Children's Services professionals in 2004; studies of professionals working in the same organisations in 2012; and a comparison of the two. These two dates can be seen to represent the beginning and the end of a period of significant investment and expansion of Children's Services following the introduction of the Every Child Matters: Green Paper [10] the global economic crisis [23], and the introduction of a range of austerity measures entailing cuts in public funding following the election of the Conservative-LibDem coalition government in 2010 [2] The longitudinal approach enabled identification of consistencies and disparities, stability and transformation, in order to clarify how professionals experienced shifts in organisation and practice and gain an understanding into what did and did not facilitate change.

The need for a better understanding of professional behaviour within these newly reconfigured Children's Services is highlighted by Warmington [25] who states that "professionals often find themselves located in complex, vertiginous settings in which individual and collective practices are undergoing radical transformation that necessitates new learning and knowledge creation". He believes that there is a general underestimation of the "qualitative changes" needed in professional practice with government policy and related literature failing to capture "the landscape of emerging practice" [25].

The need to better understand the change process within large complex organisations is also highlighted in the independent inquiry into the care provided by Mid Staffordshire NHS Foundation Trust in England, which found that patients were routinely neglected because of a preoccupation with cost cutting, targets, and processes [15] These findings act as a stark reminder of the problems that can occur if organisations, that have responsibility for the care and welfare of vulnerable individuals, fail to appropriately prioritise their work. It was therefore the intention of the research to use Cultural Historical Activity Theory to learn lessons from the events that took place between 2004 and 2012 to help prevent a similar lack of prioritisation.

Cultural Historical Activity Theory (CHAT) was chosen as the analytical framework in order to help develop insights into individual and collective professional behaviour. CHAT helps develop theoretical understanding of the factors which mediate human behaviour and derives from social psychology as developed by Lev Vygotsky in the USSR in the early part of the twentieth century [13], [18]. In the past thirty years Yrjo Engeström has developed the work of Vygotsky and has established CHAT as a research tool with which to study organisational and professional learning. 


\section{The Policy Discourse}

In 2004 the UK was in the middle of a thirteen year Labour administration that rode on a putative economic boom, managed by an 'iron chancellor'. The New Labour government's social democratic credentials were in large part predicated upon its children and families policy having renamed the Department of Education and Skills, the Department of Children, Schools and Families and initiated the Every Child Matters agenda. By 2012 the UK, like much of the west, struggled in the aftermath of a global financial crash, one of the consequences of which was reduced welfare provision. The UK was now governed by a Conservative-Liberal Democrat coalition concerned with cutting the deficit through austerity policies that included an increasingly marketised, managerial model of Children's Services. Despite these differences in the content of the 'New Labour' and Conservative-LibDem coalition government's policies, commentators have argued that there remains a similarity in the philosophy which underpins their attitude to the provision and delivery of public services. Cerny and Evans [4] believe that 'New Labour' adopted a policy agenda which reflected the "continuing transformation of the British industrial welfare state into a competitive state" [24].

The notion of a 'competitive state' implies a quasi-marketised approach, one in which discourses of efficiency, accountability and managerialism have come to dominate public provision. The coalition government that was elected in 2010 can be seen to have continued this neo-liberalist agenda of reform by introducing the concept of the 'Big Society' which further attempted to reform local government (and governance) structures within England through the abolition of monitoring bodies such as the Audit Commission and the introduction of the Localism Bill [16].

This commitment to the concept of localism has its roots within a neo-liberalist desire to reduce the size of the 'state' by increasing the role that civil society plays in not only filling the gaps left by the reduction in the size and power of the state machinery but by also creating new innovative ways of tackling social exclusion and social inequality [16]. However this drive towards 'localism' can be seen to have been derailed due to the "political expediency of budget cuts" [22] needed at a time of public sector austerity which led to a proposed $27 \%$ reduction in public pending within the 2010 spending review. This together with a failure of the LibDems to embed any distinctive "blend of liberalism and community politics" [22] has led to what Lowndes and Pratchett believe is an incoherent national policy context that is still heavily influenced by the deeply entrenched policies of 'new labour' which have embedded the concept of performance and partnership into the working practices of all local authorities rather than the poorly defined and articulated notions of the Big Society. However the recent election of the Conservative party (2015) removes the restraint imposed through the previous coalition with the Liberal Democrat party and provides the opportunity to dismantle the public sector in line with their neoliberal political philosophy rather than as a symptom of the global economic crash of 2008.

\section{Methodology}

The research focused upon the Children's Service portfolio of a local authority located within the West Midlands region of England. The first round of data collection took place just as the 2004 Children Act [11] was introduced. The second round of data collection took place in the same local authority eight years later during another period of change and transformation. Data was collected using semistructured interviews with a range of Children's Service professionals. Activity system categories were used to code the interview schedule in order to facilitate an objectified comparison of findings within and between both phases of data collection.

One of the key challenges for the research was in trying to define 'professional behaviour' and also in deciding how this could be identified and investigated. In order to achieve this I drew heavily upon Cultural Historical Activity Theory [6] which offered a way of defining behaviour and also a framework which would help structure data collection and analysis. CHAT uses an activity system as the minimum unit of analysis and is made up of a number of categories which interact to influence and shape human behaviour [12]. An activity system (see Figure: 1) is constructed from six different categories which influence collective human behaviour within any given context. These categories were used as codes [5] within the interview schedule with the theoretical principles of CHAT being used to analyse the data collected. CHAT therefore formed the analytic framework through which all stages of the data collection, analysis and resonation took place.

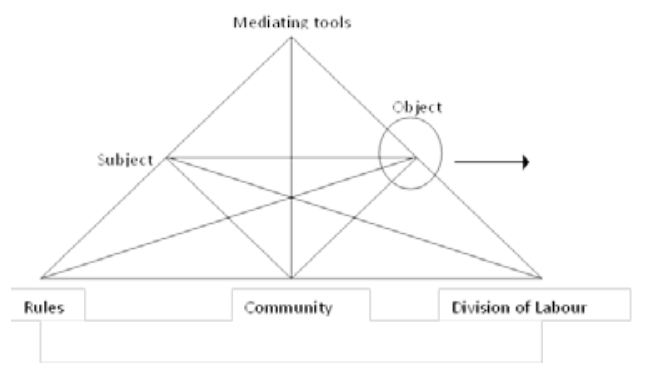

Figure 1 . The structure of an activity system 
Although embedded within a highly complex theoretical approach the concept of an activity system proved to be a very useful tool for investigating professional behaviour and allowed for a consistent comparison of the findings between; all interviewees within and across each phase of data collection (2004 and 2012). The different categories within an activity system allowed for an examination of each interview from a variety of different perspectives. In this way it avoided the very thing that Vygotsky [18] was all too well aware of; that of using consciousness to analyse consciousness.

The concept of historicity and multi-voicedness as described by Engeström [13] are also highly suited concepts for a longitudinal research study which necessitates a comparison of multiple responses within and between two dates. In fact these two concepts can be seen to underpin the study; with the concept of historicity acknowledging the extent to which practice is informed and influenced by the previous generations; and "multi-voicedness" [13] accounting for the contradictions and tensions within the system, which if resolved, may offer the potential for practice to be changed and transformed. Multi-voicedness in particular creates a particularly useful principle in that once identified it can become the focus for future transformation of practice. It therefore provides the opportunity for the research findings to be of practical operational value, however there is no direction as to how each of these concepts can and should be identified and applied which can and did create a certain degree of uncertainty at the early stages of data analysis.

\section{Key findings of the research}

How then has the neo-liberalist policy narrative that has been outlined above impacted upon the professional behaviour for those involved within Children's Services? The following section presents the perspectives of practitioners that have lived and worked through this turbulent period and reviews the similarities and differences in professional behaviour that exist between the two dates which perhaps give insight into the future landscape of Children's Services.

\subsection{Differences in practice (2004 -2012)}

In 2004 there was considerable uncertainty and confusion as to the concept of a 'Children's Trust' which had been introduced as part of the Children Act, 2004. This uncertainty was accompanied by concern as to the implications that this had for the work of professionals associated with the development of the newly formed Children's Services. In 2012 however, following another period of reorganisation, practitioners seemed to have a much clearer understanding of the new Children's
Service structure. The Council had therefore changed from being a highly complex and highly fragmented work environment, in which a plethora of initiatives populated the landscape, to one which through a period of austerity and budget cuts was much smaller with a much clearer sense of purpose.

This clarity of purpose can be seen to have been gained through the implementation of a clearly articulated strategic plan. This is very different to 2004 where senior strategic managers were struggling to come to terms with a new professional landscape and unable to create a clear strategic vision. Despite this clarity of purpose the Council in 2012 no longer has the dominance it enjoyed in 2004 with schools and other agencies, such as the voluntary sector, becoming a much more prominent force within the Children's Service environment. The relationship that the Council had with schools in 2012, can actually be seen as a reversion to their position pre-2004 with schools once again being seen as standing outside Council structures; a situation which seems hard to comprehend considering the time, effort and funding that was invested in embedding schools within the previous Children's Trust [11] arrangements in an attempt to create a much more cohesive and integrated Children's Service environment.

Another difference that was evident in professional practice between the two dates is the business-like language that was being adopted by those who work for the Council in 2012. This is far removed from the language of 2004 which had a much more philanthropic overtone and focused around the concepts of prevention, partnership and participation. The emphasis upon working in partnership was a particular feature of practice in 2004 following recommendations of the Laming Report [19] and was seen as a revolutionary way of working which would facilitate the desired preventative approach and was seen by the Head of Integrated Children's Services in 2004 as something which was an essential aspect of professional practice. She stated;

"if we are to improve the quality of services in our neighbourhoods then the first thing we need to do is make sure that all the service providers within a particular area are all singing the same hymn sheet."

However the practice of agencies working in partnership in 2004 which was motivated via the aspirations of national policy was then seen as a revolutionary form of professional practice. However it can be seen to have a much different interpretation in 2012 where it is seen as an essential element of everyday practice due to the demands that practitioners are faced with as a result of shrinking financial and human resources. The Every Child Matter's: Green Paper [10] could therefore be seen to have initiated the current joined up approach to the delivery of Children's Services which is now 
embedded into professional practice so that "genuine integrating working” is seen to be taking place, and perhaps challenges Daniels [9] and Riddell and Tett's [24] scepticism over the feasibility of multiagency working.

Another significant difference between the two periods is the clear "customer focus" that now exists within the Council, which again, seems at odds with the more benevolent approach evident in 2004. The reference to "customers" relates specifically to the new business-like language which now conceptualises service users as a potential source of much needed income rather than as a client group in need of much needed support. This is captured in the following extract from an interview with the Integrated Service Manager (2012).

“The chief exec's looking to bring someone in with a business background ....... we need to be much sharper and business focused because we've got less money".

This is a significant change in professional philosophy whereby services, which in 2004, were free at the point of delivery, have now been redefined through the use of language more normally associated with private business as a direct result of the austerity measures and reduction in funding. Levitas [21] however, would perhaps question whether the adoption of this new business-like approach is actually a response to the global economic crisis by those who work within Children Services and would perhaps suggest that this is actually the effect of a specific neoliberalist political philosophy which has been introduced by the ConLibDem coalition and which will continue unabated by the newly elected Conservative government.

Despite the desire to transform service users into "customers" of services, there is still a focus upon identifying "need". However this move towards commercialisation of services still seems very much at odds with the earlier ambitions of Every Child Matters which was rooted in social justice for all. In 2012 services are procured once the needs of the child or family have been identified and assessed rather than the universal provision for all children that was advocated in 2004. The strategic focus of the Council could therefore be seen to have changed from one which purported to focus upon universal access to one that now has adopts the language, if not the practice, of commercial business. The focus upon; prevention, partnership and participation therefore seems to have been replaced by one which focuses upon accountability and efficiency as a direct response to the central government funding cuts which has seen investment in Children's Services fall so dramatically [4], [21].

However somewhat surprisingly despite, the dramatic rationalisation of the council, none of those interviewed seemed bitter over the changes; with practitioners viewing the previous Children's Service structure [11] as being inefficient and ineffective. This is in contrast to the current provision which was developed as a result of a systemic review undertaken in 2011 by the Assistant Director through which he was seen to create a coordinated and streamlined structure which avoided duplication and maximised efficiency via the newly formed 'Family Connect' service which acts as a hub for all children and family related services. The mistakes that took place in 2004 are now acknowledged with the Assistant Director for Children and Families who state:

"We got it wrong Paul which is my view, the government had lots of initiatives and what we did wrong was rather than integrate those projects into mainstream business we set them up as projects so we created a whole lot of silo's across the place and our view healthy schools, extended schools and services are actually all part of what we should have been doing anyway in early intervention services”.

The Council is therefore no longer made up of a range of individual initiatives and education no longer acts as "the glue in the middle" with schools now being seen as a separate agency and a potential customer. The Council can therefore be seen to have redefined itself from an organisation that once dominated Children's Services to one that now serves a specific commissioning role within an increasingly fragmented and less bounded public service environment.

The restructuring that took place in 2011 has also created a range of new occupations with wider job remits as a result of the reduction in staffing levels and funding. These wider job roles have led to a reduction in the number of complex governance structures that were evident in 2004. The rationalisation of the Council in 2012, together with a reduction in the number of national policy directives, has also facilitated a move away from a centralised governance model and has allowed more decisions to be made on a local level. This shift to a more localised decision making process seems to have created a need by the Council for practitioners to have a more flexible approach to work which is adaptable and responsive to change. Despite this need for the modern Children's Service professional to be entrepreneurial and possess increased flexibility there is now tension between this desire and the traditional rules, regulations and processes by which the Council functions. Historicity and multi-voicedness are therefore dominant forces in the Council's desire for change and transformation. The tension that exists between flexibility and the bureaucracy evident within the Council perhaps highlights why the voluntary sector is now seen to be thriving during this apparent period of national austerity as they are quick to respond to national and local need because of their independence and lack of 
regulation. In contrast bureaucracy can be seen to pervade the work of local authority based Children's Service practitioners in both phases of the research. These traditional working practices predate the Children Act (2004) and can be seen as a historical legacy of previous profession generations which can now be seen as actively preventing the development of new innovative entrepreneurial practice: a Council priority. The frustration this creates is captured in the extract below from an interview with the leisure facilities manager in 2012.

"I can only speak on a commercial base; it's like smashing a round peg into a square hole. Policies and procedures and working directive etc. that the Council run or adhere to are generally based on office workers. Now if I am competing in the private sector and I have got a couple of people I need to work extra hours. One they're not allowed to do it and sometimes I take a working time directive, casuals are not really casuals as they have to be treated as employees and given a contract; there's all sorts of anomalies that go on but yet you still have to provide your targets that you're set”.

Despite the general confusion and duplication that the introduction of the 2004 Children Act seemed to have created it was seen by a large number of professionals as providing much needed support and opportunities for all children and young people across the authority. This universal support has now gone and opportunities for all children and young people is reducing as the Council moves from a universal approach which promotes prevention, to a targeted approach for children and families who are in most need and raises an important question as to what has happened to those children and young people who fall just short of being defined as "most in need" and to the ambitions of making Every Child Matter?

\subsection{Similarities in practice (2004 -2012)}

As has been previously stated, 2004 and 2012 represent periods of significant change. Although the rationale for this change is significantly different, the confusion that existed for operational practitioners early in the change process is similar. During both periods of reconfiguration Children's Service practitioners became concerned over the implications that the proposed change had for them, individually. This level of concern created anxiety which arguably distracted them from their professional duties and responsibilities. Each interviewee therefore had a unique experience of the change process in relation to their particular professional and personal context. Policy ambitions therefore became less generic and were instead applied to a particular context within which a practitioner worked. The response to change in both years is therefore seen to be an individual phenomenon with the new approach to professional practice being individually interpreted, defined and created.

This individualised response to the demands of the changing policy context is evident throughout strategic and operational layers of Children's Services and in both periods the newly appointed senior managers could be seen to go through a learning process in which they attempt to come to terms with the new professional environment. Despite the difference in the rationales for change in 2004 and 2012, both sets of senior managers also come to the same conclusion: that a change in the philosophy of those working within Children's Services was needed in order to create a "collective identity" [17] rather than the introduction of a range of new services through the acquisition of additional funding. Both sets of senior managers can therefore be seen to be trying to develop coherent structures which attempt to support, coordinate and communicate this philosophy to all of those working within Children's Services rather than looking at specific models of service delivery.

Practitioners, in both phases of the research, are also seen to ignore certain aspects of national policy which they do not individually value or deem important. This is particularly evident in the focus that the 2004 Act placed upon the participation of children and young people within the decision making process of Children's Services which was not embraced or adopted by any practitioners in 2004 and is non-existent in 2012; or in the involvement of the voluntary sector which was never embedded into practice in 2004 and again is non-existent in 2012. Practitioners can therefore be seen to select aspects of national policy which they view as worthy of implementation and which they view as not. A similar pattern could also be seen to exist in the way that certain professional skills are valued at different times depending upon the overriding professional culture. This can be seen across the two periods and is identified in the rise and fall of roles such as children's participation workers, integrated service managers, study support managers and currently with employees with proven income generation skills. This would seem to support both Avis [1] and Giddens [16] belief that there is a need for the modern day Children's Service practitioner to be able to adapt to the demands of an ever changing professional context rather than simply possessing a particular set of core skills. This individualised approach to the work of a Children's Service practitioner is captured in the following extract with the Director of the Council for Voluntary Services which was undertaken in 2012.

"a policy just allows people to do the bare minimum and escape detection then that's one thing but if we want people to actually transform personally into a much more effective worker then 
policies don't enable that; they can provide a framework but I believe its inside and that you want to understand families better."

Another feature of professional practice however, that has remained of significant importance is the need for agencies belonging to different agencies to work in partnership with each other for the good of all vulnerable children and young people. Partnership working therefore is not only seen as a strategic ambition but can now be seen to be a feature of everyday practice. Despite embracing partnership working in this way it is somewhat surprising to find that there remains a general lack of awareness of the aims and objectives of 'other' professionals and agencies in both 2004 and 2012. This lack of awareness is evident throughout the layers of Children's Services; from senior strategic positions to those who are much more operationally focussed and is possibly explained by the traditional hierarchical management systems which remain in place and prevent the full integration of professionals from a range of different agencies and again demonstrate how historical structures and practice continues to influence and shape current provision.

As mentioned previously, the voluntary sector also remains 'outside' of the Council, throughout both phases of the research, with neither the voluntary or statutory sector agencies showing any desire to work together. Despite the antipathy which is evident between the Council and the voluntary sector; working in partnership is a recognised as an important aspect of the work of all the interviewees. However, as has been stated before this is no longer because of the Children Act (2004) but now takes place because it allows practitioners to achieve a shared object such as: meeting the needs of child and young people with the most complex of need or supporting the delivery of Family Connect. However, despite the development of new partnership working arrangements, there remains a risk that new 'effective' ways of working cannot embed because of the ever changing policy context.

\section{Conclusion}

The findings presented above highlight the unstable nature of professional behaviour together with the sense of confusion that existed during these periods of change and transformation. This uncertainty is perhaps not surprising, considering the size and complexity of the agencies that were undergoing restructure and it perhaps challenges Lave and Wenger's [20] concept of a stable and cohesive community of practice. However the confusion which was evident in 2004 did seem to resonate with Vygotsky's [18] notion that learning; is underpinned by discontinuity, conflict and displacement. The findings of the research therefore seem to support an understanding of human behaviour which is complex, idiosyncratic but with occasional phases of cohesion around certain key processes. In this way Engeström's concept of "negotiated networking” [14] seems particularly applicable, as does Holland's et al [17] concept of "collective identity" and Castells [3] concept of a network in which individuals work together on shortterm projects in a process of forming and reforming their behaviour.

However it also highlights the metamorphic nature of organisations that can be seen to have taken place over time through a process of rationalisation and restructure rather than through individualised learning. The underpinning neoliberal policy narrative can also be seen to be continuing to write the history of children services and is one that will continue to be rewritten as the Conservative Party's election victory in May 2015 provides a mandate for the dismantling of the public sector machinery which puts in danger the very survival of the 'public service practitioner' within the increasingly hostile marketised environment and necessitates a rethinking of the skills set needed to function effectively within the Children' Services of the future..

\section{References}

[1] Avis, J, "Workplace learning, knowledge, practice and transformation”, Journal for Critical Education Policy Studies, Open Access, 2010, 8 (2): pp. 165-193.

[2] Biressi, A., and Nunn, H., "Selfishness in austerity times”, Journal of Politics and Culture, Lawrence and Wishart, London, 2014, 56 (1): pp. 54-66.

[3] Castells, M., The Rise of the Network Society: The Information Age, Economy, Society and Culture, 1, Blackwell, Oxford, 2000.

[4] Cerny, G. P. and M. Evans, "Globalisation and Public policy under 'New Labour'”, Policy Studies, Taylor and Francis Publishing, Oxford, 2004, 25 (1): pp.51-65.

[5] Cohen, L., Manion, L. and K., Morrison, Research Methods in Education, 7th edition, London, Routledge, 2011.

[6] Cole, M., Cultural Psychology: A Once and Future Discipline, Harvard University Press, Cambridge, 1996.

[7] Cole, M., Engeström, Y. and O. Vasquesz, Mind, Culture and Activity, University Press, Cambridge, 1997. 
[8] Daniels, H., Introduction to Vygotsky, Routledge Publishing, London, 2005.

[9] Daniels, H, “Analysing trajectories of professional learning in changing workplaces”, Culture and Psychology, Sage Publications, London, 2011 17(3): pp. 359-377.

[10] Department for Education and Skills, Every Child Matters, HMSO, London, 2003.

[11] Department for Education and Skills, Children Act, HMSO, London, 2004.

[12] Engeström, Y., R. Miettinen and R. Punamaki, Perspectives on Activity Theory (Learning in Doing: Social, Cognitive and Computational Perspectives), Cambridge University Press, Cambridge, 1999.

[13] Engeström, Y, "Expansive Learning at Work: toward an activity theoretical reconceptualisation", Journal of Education and Work, Taylor and Francis Publishing, Oxford, 2001, 14 (1): pp.133-156.

[14] Engeström, Y., The new generation of expertise: seven theses, in Rainbird, H,. A., Fuller and A. Munro (Eds) Workplace learning in context, Routledge, London, 2004.

[15] Francis, R., The Mid Staffordshire NHS Foundation Trust Public Inquiry. London, HMSO, 2012.

[16] Giddens, A, Runaway World: How globalisation is Reshaping Our Lives, Profile Books Ltd, London, 2002.

[17[ Holland, D., "Social Movements and Collective Identity: A decentred dialogic view". Anthropological Quarterly, The George Washington University Institute for Ethnographic Research, Washington, 2008, 81 (1): pp.95-125.

[18] Kouzulin, A., "The concept of Activity in Soviet Psychology”, American Psychologist, The American Psychological Association, Washington, 1986, 41 (3): pp.264 - 274.

[19] Laming, L., The Victoria Climbié Inquiry, Report of an Inquiry by Lord Laming, HMSO London, 2001.

[20] Lave, J. and E. Wenger, Legitimate peripheral Participation in Communities of practice in McCormick, $\mathrm{R}$ and C. Paechter, Learning and knowledge. Paul Chapman publishing, London, 1999.
[21] Levitas, R., “The Just's Umbrella: Austerity and the Big Society in Coalition policy and beyond", Critical Social Policy, Sage Publications, London, 2012, 32: pp. 320-342.

[22] Lowndes, V. and Pratchett, L., "Local Governance under the Coalition Government: Austerity, Localism and the 'Big Society', Local Government Studies, Taylor and Francis Publishing, Oxford, 2012, 38 (1): pp. 21-40.

[23] Rapoport, A. and Gerts, A, "The Global Economic Crisis of 2008-2009: Sources and Causes”, Problems of Economic Transition, Orebro University, Sweden, 2010, 53 (6): pp. 45-62.

[24] Riddell, S and Tett, L., "New Community Schools and Inter-agency working: assessing the effectiveness of social justice initiatives", London Review of Education, Taylor and Francis online, 2004, 2 (3): pp. 219-228.

[25] Warmington, P., From 'activity' to 'labour': commodification, labour-power and contradiction in Engeström's activity theory, Critical Social Studies, Sage Publications, London, 2009, 10 (2): pp. 4-19. 